\title{
Decency in Resource Allocation versus Duty to Care
}

\author{
Samina Yasmeen ${ }^{*}$
}

Aga Khan University Hospital School of Nursing and Midwifery, Pakistan

*Corresponding author: Samina Yasmeen, Aga Khan University Hospital School of Nursing and Midwifery, Pakistan, Tel: +92 3215656854; E-mail: saminayasmeen71@gmail.com

Received date: October 12, 2016; Accepted date: November 09, 2016; Published date: November 16, 2016

Copyright: @ 2016 Yasmeen S. This is an open-access article distributed under the terms of the Creative Commons Attribution License, which permits unrestricted use, distribution, and reproduction in any medium, provided the original author and source are credited

\begin{abstract}
Duty to care is the first oath that each nurse must take while entering in nursing profession. It's not only mean to provide care but also protect the patient from potential harm in term of giving infection from himself/herself. This commentary paper is based on a scenario, addressing an ethical conflict between a duty nurse and management, where administration wants a sick nurse to give care to an organ transplant patient. This paper also aimed to give critical review and identify the possible solution for such a routine ethical issues.
\end{abstract}

Keywords: Resource allocation; Duty to care; Immunocompromised; Non-maleficence; Beneficence

\section{Scenario and Introduction}

In surgical intensive care unit, as per routine, I was assigned with a renal transplant patient but that day I was suffering from upper respiratory tract infection. I requested my shift supervisor, to please assign me any other patient rather than the transplant patient, as, I am suffering from infection. The supervisor disagreed with me due to the shortage of staff and forced to do the duty with assigned patient.

Here an ethical dogma arises. Doing, fairness in resource management at one side, and on the other side letting the duty to care; Is, this balancing moral obligations?

Being a health care provider we knew that, duty to care is the obligation of professionals to perform their practices with liability in order to reduce the risk of possible harm to the patients [1]. Immunocompromised person is the one, who is more prone towards infection and develop disease as a result of low immunity to combat with the disease. It is necessary for nurses to know that the ethical underpinning of duty to care stem from the principle of nonmaleficence [1]. Non-maleficence is not to do harm [2].

On the basis of this bioethical principle, we as nurses have ethical obligation to provide care for those patients come across in our day-today practice but not to put patient on risk intently, as evident in above scenario. In addition, very limited focus has been observed on the "care for caregivers" with this implication that if nurses are sick, can't care for themselves, then how they will be able to provide care to others? As American Nurses Association code of ethics suggested that nurses have same duty towards self as they care for others [3]. So, it gives the awareness among health professionals that they have not only ethical obligation towards their patients but also towards themselves. They are as much important as others when they feel sick.

\section{My Position}

Here, I consider my position ethically strong. As patient was Immuno-compromised and should not be exposed to infection at any cost, while on the other hand, nurse was also suffering from infection.
While keeping in view the principal of no-maleficence and duty to care I never wanted to put my patient on more risk. Morally I was on right path as my professional code of ethics suggested that nurses have obligation to protect patient as well as themselves [3]. Though, organization has the right to assign duties, but one must not forget that an infected care provider can transmit infection to the Immunocompromised patient through care delivery.

Moreover, "those nurses providing care to transplant patient should provide infection free and safe environment" [4]. Next to it, supervisor has own duty being fair towards organization, patient, and nurse. Additionally, the commitment of the organization for every client is to provide maximum benefits and quality care to patients and help in reducing the potential health risks [2].

\section{Counter Arguments}

On the other side of the picture, supervisor was also true but she was letting the principle of fairness. Fairness is balance between equal and unequal [2]. So compelling for duty in unhealthy situation can potentially harm to patient as justified by literature. But the supervisor has/her own duty, obligation and liability to be fair towards organization and make subordinates to perform the tasks assigned to them. Likewise, "Any individual being an employee has promised to remain fair and unbiased towards the organization" [5].

On the other side, supervisor was on right track. Due to shortage of staff, supervisor was doing justice with system but on the other hand letting the right of nurse and patient. They both (Nurse and Patient) also need fairness since having same right of health. According to code of ethics and medical science health care provider is liable to treat patient with honesty and provide maximum benefits.

\section{Justification of Position}

In this conflicting situation, I consider my position is ethically sound. Although, our moral obligation is to provide care but also it is our ethical requirement to keep in mind the element of nonmaleficence while caring to Immuno-compromised patients. However, sometimes seems difficult to remain fair dealing in such dilemmas. On the other hand, if we see from management perspective, supervisor was right because of limited work force and no alternative due to 
Citation: Yasmeen S (2016) Decency in Resource Allocation versus Duty to Care. J Clin Res Bioeth 7: 1000292. doi:

Page 2 of 2

shortage of staff. So, both were correct on behalf of their moral compulsions.

\section{Conclusion and Recommendations}

While concluding, I would suggest that the responsibility of management is to have alternatives in such conflicting situations. Since, supervisors remain very strict with traditional model of management where, only duty is the preference but always a deprivation of ethical component. There is a strong need to modify these management models in the light of current ethical dilemmas that formerly facing in our daily life. Policies for improving the quality practices to be established and implemented in such a way that management's focus should also be on the health of care givers. Perhaps, it could be suggested that rotation of staff is a good alternative in such kind of dilemma. In this way we can save the patient, staff, and fulfill our ethical obligations. Furthermore, it could be a footstep for management to retain human resource as a backup force to handle such emerging situations. As a result, steadiness could be possible between ethics of care and fairness in resource allocation.

\section{References}

1. Schroeter K (2008) Duty to care versus duty to self. J Trauma Nurs 15: 3-4.

2. Beauchamp T, Childress J (2001) Principles of biomedical ethics (5th edn), New York: Oxford University Press.

3. (2001) Code of ethics for nurses with interpretive statements. American Nurses Association, Nurses Books Organization.

4. Griffin JP (1986) Nursing care of the immunosuppressed patient in an intensive care unit. Heart \& lung: J Critical Care 15: 179-186.

5. Caldwell C, Floyd LA, Atkins R, Holzgrefe R (2012) Ethical duties of organizational citizens: obligations owed by highly committed employees. J Bus Ethics 110: 285-299. 